\title{
Sobre o ensino das artes visuais: o estúdio de pintura como laboratório ${ }^{1}$
}

\section{Jociele Lampert ${ }^{2}$ (UDESC) Fábio Wosniak ${ }^{3}$ (UDESC)}

\section{Resumo}

O texto apresenta reflexões sobre o Grupo de Estudos Estúdio de Pintura Apotheke da Universidade do Estado de Santa Catarina - SC, bem como, situa - contexto da Arte como Experiência de acordo com Dewey (2010), e aponta para o lugar da prática artista e prática pedagógica para o artista professor. O Grupo de Estudos Estúdio de Pintura Apotheke, é um Programa de extensão, vinculado ao Grupo de Pesquisa Entre Paisagens CNPq/UDESC. Como Programa de extensão torna-se um laboratório, no sentido que articula vivências, experiências e propostas de ensino/aprendizagem pautadas em pesquisa.

'Entre Paisagens' configura não apenas a nomenclatura do Grupo de Pesquisa CNPq/UDESC onde me situo como professora, e direciona uma práxis de fazer artístico como pesquisa, que evidencia direcionamentos ao ensino, pesquisa e extensão, na via da Universidade. Neste entre, situa-se a prática de olhar sobre a formação inicial de professores, que tem como eixo principal a construção e estrutura da experiência poética de pesquisa sobre e em Artes Visuais. Seguindo esta perspectiva, e evidenciando os procedimentos metodológicos e pedagógicos, instaurados no espaço/tempo/lugar de minha 'professoralidade', imersa no Ensino Superior, bem como, das possibilidades

\footnotetext{
1 Este artigo foi publicado no Livro: SANTOS, Luciane M. dos; PREVE, Ana Maria Hoepers (orgs). Laboratórios de Ensino em Cursos de Licenciatura: Relato de experiências e Práticas. Porto Alegre: Alcance, 2016, p. 88-98.

Desenvolveu pesquisa como professora visitante no Teachers College na Columbia University na cidade de New York como Bolsista Fulbright (2013). Professora Adjunta na Universidade do Estado de Santa Catarina. Atua no Mestrado e Doutorado em Artes Visuais PPGAV/UDESC na Linha de Pesquisa de Ensino de Artes e na Graduação em ArtesVisuais DAV/UDESC. É membro do Grupo de Estudos e Pesquisa em Arte, Educação e Cultura UFSM/CNPq. Membro/Líder do Grupo de Pesquisa Entre Paisagem UDESC/CNPq. Coordenadora do Grupo de Estudos Estúdio de Pintura Apotheke (UDESC).
}

3 Doutorando em Artes Visuais na Linha de Pesquisa de Ensino das Artes Visuais PPGAV/UDESC; Mestre em Artes Visuais na Linha de Pesquisa de Ensino das Artes Visuais PPGAV/UDESC; Pedagogo e Psicanalista. Membro/Pesquisador do Grupo de Pesquisa Arte na Pedagogia (Mackenzie/SP), Membro/Pesquisador do Grupo de Pesquisa Entre Paisagem (UDESC/CNPQ) e integrante do Grupo de Estudos Estúdio de Pintura Apotheke (UDESC). Editor associado da Revista Apotheke.

$$
=106=
$$


e potência da articulação entre o saber/fazer da prática docente e artística, construí, um Grupo de Estudos, intitulado, 'Estúdio de Pintura Apotheke', que representa a busca por pesquisas, ancoradas na paisagem da experiência artística, que pode gerar outras instâncias de produção e reflexão, frente a Educação.

APOTHEKE é um palavra que tem origem grega, do substantivo apotheke, que designava armazéns do porto de Atenas na Grécia Clássica; Também de origem germânica, indica a origem da palavra botica, boticário ou farmácia. A escolha por esta nomenclatura, decorre da percepção da botica como lugar de laboratório, de um labor experimental. O que aproxima-se da proposta do grupo de estudos, tendo a pintura como eixo norteador para o processo artístico e prática pedagógica, considerando o campo ampliado e os possíveis desdobramentos para o pensamento visual. Neste espaço, questões sobre Arte como experiência, ou ainda, sobre o lugar de quem produz e de quem ensina Arte ou simplesmente de um saber/fazer/sentir competente ao artista professor, surgem constantemente e evocam a investigação sobre o modo como o ensino/aprendizagem influencia atitudes, crenças, valores, bem como, estudos e produções artísticas dos sujeitos (artistas professores) pesquisadores, envolvidos com o grupo. Propõe-se investigar a Educação em tessitura do espaço/tempo, e das articulações cartográficas, entre o professor e o ser artista professor, com a clave sobre a prática artística articulada aos saberes pedagógicos. De acordo com o projeto de pesquisa "Arte Educação pela pintura: a produção artística do artista professor", constata-se:

O grupo de estudos Estúdio de Pintura Apotheke surge do Projeto de pesquisa "Arte Educação pela pintura: a produção artística do artista professor". Este apresenta uma tessitura coerente ao contexto do ensino de arte contemporâneo. Pois, deriva da articulação possível entre teoria e prática, assim como, pode abordar questões pertinente a quem ensina e produz Arte. o' seja, a escolha da articulação entre Arte Educação e pintura, em meio as questões que permeiam a construção do conhecimento do artista/professor/pesquisador, decorre da busca permanente por amplo repertório de quem ensina e produz e pesquisa no contexto pictórico. (LAMPERT, 2013, p. 3)

Formado por 23 participantes, dentre estes, professores da UDESC, outras IES, alunos de Graduação e Pós-Graduação em Artes Visuais, e professores da Rede Pública de Fpolis/SC. Site: http://www.apothekeestudiodepintura.com

$$
=107=
$$


Há duas linhas que pairam sobre o tema do artista professor: a primeira, instaura que é preciso ter produção, reconhecimento, receber crítica, curadorias e ser legitimado pelo sistema de circuito de Arte; A segunda, (a qual, penso fazer parte), aponta para a percepção sobre o tema, evidenciado por eixos: de perceber no ato criativo a concepção de planejamento e metodologia para aulas, bem como, da relevância em ter processos criativos singulares e experimentações (seja por meio de cadernos, diários, anotações, até em produção sistemática que pode estar (ou não) inserira em um sistema e circuito de Arte, ou da conversa com artistas e reflexões sobre outros textos e diálogos e exemplos de outros processos. Ou seja, para ser um professor artista, (é necessário a pesquisa ser inerente ao processo de criação), também ponderar sobre o lugar/tempo/espaço de produção e recepção do 'objeto' artístico. Assim como, compreender a produção de conhecimento sobre o ensino/aprendizagem, articulada com o espaço da sala de aula, da Escola, do estúdio do artista ao diário, ao caderno e/ou à cidade, onde deambulamos sobre diferentes visualidades, e que, poderá servir de lugar para outros processos formativos, fora de conteúdos e currículos, a isto nomeia-se transcognição, segundo Sullivan (2005).

Como professora de Graduação e Pós-Graduação em Universidade pública no Brasil, venho me questionando: como desenvolver articulação entre teoria e prática no ensino/aprendizagem em Artes Visuais? Também questiono, como são os profissionais que saem da Universidade hoje, dos Cursos de Artes Visuais? Independente de ser professor, artista, artista professor, ou mesmo, artista educador, ocorre refletir sobre como os profissionais reverberam e articulam a potência criativa entre fazer e pensar Arte, e mais, qual o lugar da pesquisa em Arte e sobre Arte, na vida profissional desse sujeito?

Dentro de um quadro amplo, do lugar onde situa-se a pesquisa em Arte e sobre Arte, o artista professor está urdido em uma interface crítica e criativa, seja ministrando aulas, organizando eventos, desenvolvendo pesquisas, realizando exposições ou desempenhando funções administrativas em projetos e no contexto universitário.

Alan Thornton (2013), questiona sobre a construção da identidade do artista professor pesquisador: 1) Como eu me identifico em minha profissão? 2) Com quais títulos, regras, práticas, conhecimento, valores e vocações os outros me identificam? o autor, refere-se aos rótulos e conceitos, com que, frequentemente lidamos como artistas professores pesquisadores no contexto onde nos 
situamos como tal. Cabe salientar, que todo o objeto artístico poderá ser passível de dinâmicas pedagógicas, políticas e discursivas. Também relevante apontar que a Arte que ensinamos na Universidade é diferente da Arte, que circula no sistema e mercado de Arte, que é diferente da Arte que ensinamos na Escola. Trata-se do mesmo cerne (Arte), e no entanto, com objetivos e proposições diferenciados, (Lampert, 2009), o que pressupõe a construção de pensamentos e ações em instâncias distintas, que invadem práticas artísticas e saberes pedagógicos. Desta forma, minhas reflexões incidem sobre o tema do artista professor.

O termo foi usado inicialmente por George Wallis, em meados do século dezenove, e vem sendo construído desde então, para firmar um retrato pedagógico da identidade associado a práxis do fazer/saber Arte. Desde então, uma rede de ações, textos/teorias e práticas foram desenvolvidas, para entender o processo de pensamento que discute o lugar do artista professor, que é um processo conceitual de ampliar um modo artístico e estético de pensar o ensino de Arte. Assim, conforme Joaquim, p. 148-151:

\footnotetext{
O professor-artista surge, no campo da literatura em torno da educação artística, como uma figura na qual confluem diversas tensões que advêm do cruzamento de dois campos diferentes, o professor e o artista, fazendo com que quem nele se inscreva esteja sujeito também a essas forças [...]" "Assim se por um lado encontramos alguns artistas que se consideram professores, alimentando uma atividade da outra como algo essencial e inevitável. Por outro, temos artistas que desejam manter alguma distinção entre o seu lado artístico e o ensino, oferecendo algum entrave e distanciamento aos termos "educação" ou "ensino". [...] Isto quer dizer que as tensões que rodeiam o termo professor-artista podem assumir várias formas, pelo que a pessoa que a ele se associa não terá necessariamente que se colocar numa posição rígida, podendo assumir uma força de expansão, algo em movimento.
}

Para Camnitzer (2015), a Arte foi deixada de lado pela Educação, porque supõe-se um instrumento emocional e expressivo, que utiliza uma simbologia imprecisa (quanto não totalmente subjetiva), por outro lado, se supõe que Arte não pode competir com a escrita e a matemática, e assim, seria incapaz de funcionar como algo útil, para que tenha a ver com o conhecimento. Assim, apontase para uma ideologia utilitarista do conhecimento. No entanto, Arte é uma forma de pensar, mais que um instrumento. No sentido amplo, não se refere apenas a objetos "sacralizados ou adorados" (que chamamos obras de Arte), não se trata de negar fantasia, mági- 
ca ou a capacidade de maravilhar-se com o que é produzido, mas há de enfatizar a capacidade de instaurar um pensamento visual com mais propriedade racional (mesmo que percebido como subjetivo). Do mesmo lado, Educação tão pouco deverá ter o sentido de ler, escrever e fazer cálculos, mas sim, 'formar' pessoas capazes de pensar criticamente, que sejam capazes de questionar e utilizar o pensamento criativo. Não sendo Educação, uma mera manutenção ou instrumento (também) de controle do status quo e manutenção do Estado.

Assim, problemas geram respostas e respostas geram outros problemas, e isto obviamente, não cabe apenas no campo do ensino de Artes Visuais, e sim, trata da área de Educação amplamente. Refletese sobre a conjunção entre Arte e Educação, e a noção de que Arte tem que ser uma parte do processo. Não se trata de entender "Arte na Educação" isto seria ainda, seguindo as reflexões de Camnitzer (2015), um pensamento esquemático e fragmentado. Ler e escrever, não são atividades distintas de ver e desenhar, não é possível apartar conceitualização e questionamento de um processo de criação, desta forma, ter uma visão multi, poli ou interdisciplinar claramente amplia o repertório disponível para entender os elementos básico de um problema, e assim, Arte não pode ser uma disciplina ancorada em artesania ou fábrica de objetos, mas sim um meio ou lugar para organizar e expandir conhecimento, isto porque é um meio de transbordar e transgredir em diferentes áreas e metodologias, que questionam o próprio conhecimento e sistema.

Trata-se de um exercício sobre o 'duo', sobre o duplo, no sentido de percorrer fronteiras, ciente do risco, não somente criar uma zona de contato entre o estúdio e a sala de aula, mas perceber em ações e dinâmicas, que é possível uma colagem. Compreende-se que a aula de Arte (Lampert, 2009), deverá ser um contexto multiplicador através da pluralidade de confluências existentes em seu cerne, assim, a colagem propiciaria estratégias conceituais e para Garoian e Gaudelius $(2008, \mathrm{p} .23)$ :

Dada a posição da colagem como uma forma usada para atrair consumo, ela não é, coincidentemente, a forma de discurso mais amplamente usada pelos sistemas mediados de massa de televisão, publicidade, noticiário, cinema e Internet. Além disso, considerando o excesso de material visual disponível nos jornais, revistas e outras formas de cultura visual, virtualmente cada professor de sala tem empregado a colagem como um processo rápido, fácil e barato de produção de imagem para os estudantes ilustrarem o que eles aprendem em várias disciplinas acadêmicas. 
No entanto, a colagem poderá ser vista não como procedimento ou meio somente de um fazer artístico tecnicamente concebido, mas sim, evidenciar a dimensão estética e narrativa, entendendo a colagem como um eixo conceitual que permeia a elaboração crítica do contexto. Na colagem há uma indecisão, narrativa de caráter representacional ou anti-representacional (seja qual for o caso), tratando-se de um emblema para a cultura contemporânea, assim é necessário que seja proposto ao ensino de arte uma atenção crítico/pedagógica sobre a colagem.

Assim, partindo da interação (ou integração) entre theoria, práxis e poesis entende-se um princípio onde são acolhidos sentidos múltiplos que acabam por percorrer a tensão e a pulsão na Arte e Educação. Compreende-se que a pesquisa em Arte, que elabora um pensamento sobre o processo criativo, não acaba em um objeto artístico, e sim pressupõe a construção de um pensamento visual que pode ser subjetivado em meio às questões que permeiam a cultura visual. Desta forma, perceber o contexto relacional e o interstício social que a Arte pode apontar, e isto não é negar a expressividade artística ou poesia ou fantasia, como já foi dito, mas pressupõe entender a Arte como produção cultural.

Se pensarmos o artista e sua obra, a poética enquanto relação de diálogo do processo criativo no fazer plástico e em correlação, pensarmos a questão do professor e suas articulações na ação pedagógica, certamente encontraremos processo criador. Não é o processo de construção plástica, mas sim a poética do ato criador exercido no cotidiano da sala de aula, isto denota pensar o processo artístico paralelo às questões que permeiam o ensino da Arte. Construir esta poética é tarefa árdua, é amarrar a área de conhecimento a implicações imbricadas no processo educacional. Levando-se em consideração que estas questões e tantas outras são trabalhadas nos cursos de formação, de acordo com Lampert (2005), é questionável o porquê ainda encontrarmos professores em escolas (muitas vezes recém formados) trabalhando de forma desconexa da realidade do aluno, sendo extremamente conteúdista, aplicando provas, propondo atividades meramente pelo fazer técnico, e sem fim educacional algum, ou por um mero valor cartesiano. 

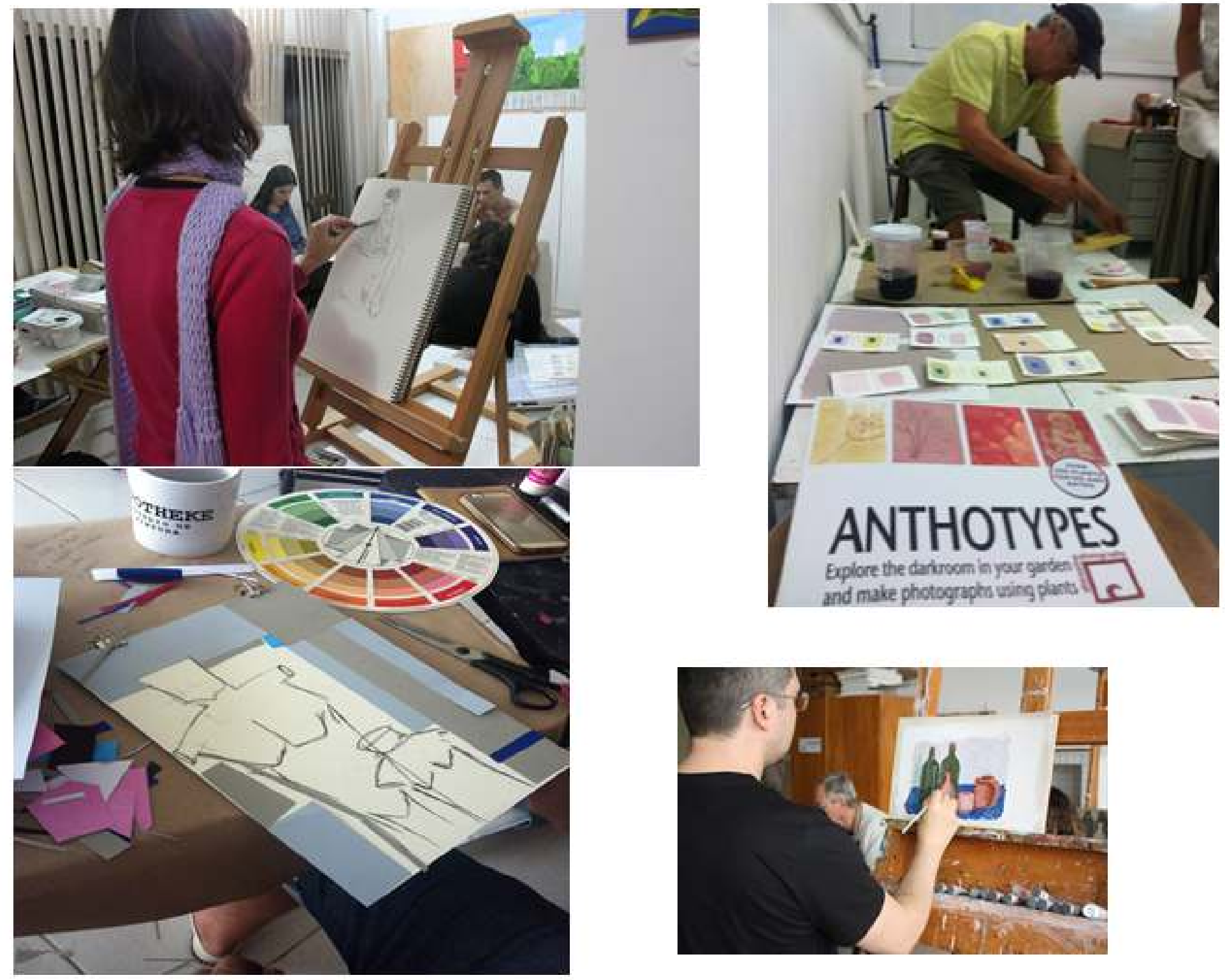

Imagem 1: Grupo de Estudos Estúdio de Pintura Apotheke, 2014 - 2015. Estudos de modelo vivo, colagem, natureza morta e anthotypes. Foto: Acervo do Grupo. 


\section{Arte como Experiência}

A constante interação entre sujeito e ambiente, juntamente com os resultados dessa relação, será o que constituirá uma experiência. Neste perspectiva, vale lembrar que Dewey fundou uma ESCOLA LABORATÓRIO, vinculada ao Departamento de Educação na Universidade de Chicago (1894 - 1904), onde a experiência era aproximada do contexto relacional dos sujeitos, e não evidenciada em disciplinas fechadas em conteúdos. Na relação entre a Arte e a Estética, o filósofo afirma que o trabalho poético, desenvolvido em uma perspectiva da filosofia da experiência, seria o clímax da sofisticação entre a união dos saberes - afetivo, intelectual e prático (DEWEY, 2002). Assim, as Artes oferecem vitalidade e aprofundam o conhecimento das experiências acumuladas, porque

\footnotetext{
Toda arte envolve órgãos físicos, como o olho e a mão, o ouvido e a voz e, no entanto, ela ultrapassa as meras competências técnicas que estes órgãos exigem. Ela envolve uma ideia, um pensamento, uma interpretação espiritual das coisas e, no entanto, apesar disto é mais do que qualquer uma destas ideias por si só. Consiste numa união entre o pensamento e o instrumento de expressão. (DEWEY, 2002, p. 76) .
}

É justamente na integração entre o pensamento e o instrumento de expressão que se pode esboçar uma ideia do que o autor nos comunica a respeito da experiência singular/estética. A experiência para Dewey é um processo do viver que relaciona-se de maneira intensa e contínua entre o mundo e o sujeito. Dessa relação brotam conflitos, resistências, impressões. Destes elementos, por sua vez, emergem as experiências, envoltas em ideias e emoções. É, portanto, neste conceito instaurado por Dewey que uma filosofia da experiência para a Arte/Educação contemporânea torna-se pertinente.

A experiência singular é também uma experiência estética, tendo em vista que em ambas as experiências há consumação, e nunca cessações - como no caso de uma experiência intelectual. Neste sentido, a experiência intelectual é diferente da experiência singular/estética. A primeira tem como matéria-prima símbolos e signos, e exige uma conclusão, um encerramento. É justamente por sua natureza conclusiva que gera incertezas. Ao contrário, a experiência singular/estética reside em fluxos constantes, possui lugares de repouso, unidade, e o seu desfecho é atingido por um movimento ordeiro e orga- 
nizado. O material vivenciado, ao mesmo tempo em que é marcado pelas percepções, é transformado pelas experiências anteriores. "A conclusão é uma consumação, e não uma cessação. Esta experiência carrega um caráter individualizador e autossuficiente." (DEWEY, 2010, p. 110)

A experiência singular/estética é uma espiral, seu fluxo contínuo unifica a percepção entre o que é feito e o que é suportável; cria conexões com experiências anteriores - uma observação constante entre o que existiu, existe e existirá, o processo é vivenciado conscientemente. A ansiedade e as frustações, que fazem parte da vida cotidiana e estão presentes no processo criativo, não são impeditivas para que a inteligência organize a consumação da experiência pulsante; discernimento entre ações e desejos, não há dicotomias, fragmentações entre inteligência e sensibilidade. Tudo se relaciona, tudo está junto, é o próprio processo do viver unificado ao ambiente tomando consciência de si - esse conjunto consciente propicia ao sujeito uma experiência singular/estética. O estético, na filosofia da arte de John Dewey, não é um fator externo e que se "lança" para a experiência. Tampouco está relacionado ao luxo, ou é idealizado por qualquer corrente de pensamento transcendental. Para o autor, "o estético (...) é o desenvolvimento esclarecido e intensificado de traços que pertencem à toda experiência normalmente completa (...) estético refere-se à experiência como apreciação, percepção e deleite" (DEWEY, 2010, p. 125-127) .

O estético presente na experiência e que faz desta uma experiência singular/estética, possui uma forma distinta de operação. o estético torna a experiência consciente através da classificação do que é percebido - a consciência do conhecimento. Esse movimento de relações está sempre unificado, incorporado com a apreensão reflexiva de experiências anteriores. O material singular da percepção estética é o equilíbrio e a proporção. Estes materiais surgem da experiência, num primeiro momento das ideias, que proporcionam ao pensamento um carácter estético. A experiência se torna predominantemente estética quando seu desenvolvimento é controlado, ou seja, quando aquilo que é feito transmite a ideia que está sendo executada. A ordem e a realização existem e sinalizam o percurso da ideia, mesmo que assinalem o desvio e a ruptura (DEWEY, $2010)$.

Dewey afirma que "a arte, em sua forma, une a mesma relação entre o agir e o sofrer, entre a energia de saída e a de entrada, que faz com que uma experiência seja uma experiência" (DEWEY, 
2010, p. 128). Como o artístico está relacionado ao ato de produção e o estético ao ato de prazer e percepção, uma obra acontece em sua completude quando o artista, ao trabalhar, assume essas duas atitudes transformando-a em uma só, ou seja, numa atitude artísticoestética. O artista, na concepção de Dewey,

comparado a seus semelhantes, é alguém não especialmente
dotado de poderes de execução, mas também de uma sensibili-
dade inusitada às qualidades das coisas. Essa sensibilidade
também orienta seus atos de criação". (DEWEY, 2010, p. 130).

Essa sensibilidade do artista está diretamente relacionada ao seu modo de pensar acerca das coisas do mundo. O artista não apenas reconhece as coisas, ele as vê, e das suas observações sobre as coisas do mundo, constitui sua percepção. O artista apreende a conexão entre o que ele está pensando e o que fará em seguida. O artista vivencia na sua consciência o efeito da sua obra. Se ele utilizar deliberadamente os materiais, não saberá a derivação do seu trabalho. Eles são veículos, não a matéria-prima para produzir a obra. O veículo, diferentemente da matéria-prima, é sempre uma forma de linguagem, expressão e comunicação. Porém, o veículo só encontra formação quando entra em contato com a consciência e a habilidade de um indivíduo.

o que está em questão é o controle do desejo. Na ideia inicial até será possível pensar em tudo, mas o "tudo" não é possível na relação que se pretende produzir - o artista encontra os obstáculos, as dificuldades da produção. Saber produzir neste limite da existência humana é aprender que a relação entre pensar e agir, culminando em uma experiência singular/estética e compreendendo que experiência não é uma soma entre o emocional e intelectual, mas que ambos ocorrem inseparavelmente, é uma das modalidades mais exigentes do pensamento. Chegar na consumação desta experiência é proteger o trabalho de uma mera sucessões de excitações (DEWEY, 2010). Sendo assim, a experiência singular/estética presente nos escritos de John Dewey é o lugar onde o autor nos esclarece sobre a proximidade desse conceito com o campo das artes e do trabalho do artista. 


\section{APOTHEKE}

ESTUDIO DE

P I N T URA

\section{Referências}

Camnitzer. Visiting Minds 2013: Pedagogía radical: el arte como educación. Panamá: Sirigua, 2015.

DEWEY, John. Arte como experiência. São Paulo: Martins Fontes, 2010 A Escola e a Sociedade A Criança e o Currículo. Lisboa: Relógio D’Água, 2002 .

GAROIAN, Charles R; GAUDELIUS, Yvonne. Spectacle pedagogy art, politics and visual culture. Pennsylvania: Penn State University, 2008. JESUS, Joaquim Alberto Luiz de. (IN)VISIBILIDADES: um estudo sobre o devir do professor-artista no ensino em artes visuais. 2013. $260 \mathrm{fls}$. Tese de doutoramento. Porto: Faculdade de Belas Artes da Universidade do Porto, 2013. Disponível em:

<http://dea.nea.fba.up.pt/sites/dea.nea.fba.up.pt/files/INVISIBILIDADES_3_se m_pagina_anexos_FINAL.pdf.>. Acesso em: 30 de agosto de 2015 .

LAMPERT, Jociele. Artist's diary and professor's diary: roamings about painting education. 2013190 fls. Relatório de Pós Doutorado, realizado no Teachers College, Columbia University, em New York/ EUA.

LAMPERT, Jociele. Arte Contemporânea, cultura visual e formação docente. 2009.159f. Tese (Doutorado Escola de Comunicações e Artes - ECA) Programa de Pós-Graduação em Artes Visuais, Universidade de São Paulo, São Paulo, SP.

THORTON, Alan. Artist, Researcher, Teacher. A Study of Professional Identity in Art and Education. Chicago: Intellect Briston, 2013.

SULLIVAN, Graeme. Studio Art as Research Practice. In: EISNER, Elliot W.; DAY, Michael D (Orgs.). Handbook of Research and Policy in Art Education. Mahwah, NJ: Lawrence Erlbaum Associates, 2004. p. 795-814. 